\title{
Process Chain Simulation of Laser Powder Bed Fusion including Heat Treatment and Surface Hardening
}

\author{
J.M. O’Brien ${ }^{\mathrm{a}}$, S.Montgomery ${ }^{\mathrm{a}}$, A. Yaghi ${ }^{\mathrm{b}}$, S.M. Afazov ${ }^{\mathrm{b}, \mathrm{c}^{*}}$ \\ ${ }^{a}$ Digital Engineering - Design and Simulation, The Manufacturing Technology Centre Ltd, Peter Jost Building, Liverpool John Moores \\ University, Liverpool, L3 3AF, United Kingdom \\ ${ }^{b}$ Digital Engineering - Design and Simulation, The Manufacturing Technology Centre Ltd, Pilot Way, Ansty Park, Coventry, CV7 9JU, \\ United Kingdom
}

${ }^{c}$ Department of Engineering, Nottingham Trent University, Clifton Campus, Nottingham, NG11 8NS, United Kingdom

*coresponding author: shukri.afazov@ntu.ac.uk

\begin{abstract}
Additive manufacturing (AM) has enabled the creation of geometrically complex parts for a range of industries. However, the nature of AM often requires multiple post processing techniques to be carried out to reach the desired material properties or required surface finish. This often involves heat treatment (HT), shot peening (SP) or laser shock peening (LSP). To date, hardly any process chain modelling has been carried out on manufacturing applications with AM. This investigation focuses on the finite element (FE) modelling of the complete manufacturing process chain of an AM impeller made of IN718, including the AM, HT, LSP and SP processes. The particular AM process applied to build the impeller is laser powder bed fusion (L-PBF). Each FE process is validated individually against experimental data before being applied to the impeller process chain. The validated data from each process is mapped to the next process in the chain to investigate the combined effects of manufacturing and post processing techniques. Results have shown that high tensile residual stresses induced by AM can be reduced by approximately $75 \%$ by applying HT. SP and LSP processes can further modify remaining tensile residual stresses after HT by inducing a layer of compressive stresses at the surface. In summary, this research work has demonstrated that the simulation of AM process chains using finite element techniques is sufficiently mature to support the product and process development of industrial AM components.
\end{abstract}

Keywords: Additive manufacturing; Heat treatment; Laser shock peening; Shot peening; Manufacturing process chain; Finite element analysis

\section{Introduction}

The process of additive manufacturing (AM) usually requires other finishing post-process operations to complete the manufacturing procedure and produce an AM component that is ready for its intended engineering or commercial use or service. Although AM is extremely versatile from a design point of view, allowing the production of internal features that would not be producible otherwise, it frequently requires additional manufacturing steps to produce the desired material properties or required surface finish. Inherently, the extreme thermal cycles in AM and the nature of metal deposition make post process operations necessary to complement $\mathrm{AM}$ in order to produce the intended product quality. Therefore, in this publication, a complete process chain is reported, including the actual AM as well as the supporting post-process operations of heat treatment (HT), shot peening (SP) and laser shock peening (LSP).

The process of AM can be numerically simulated with different techniques to reveal relevant thermomechanical information. The approach to simulation is based on either mechanics of solids or fluids. The former treats the deposited material as a solid continuum and calculates the mechanical evolution of the deposited material once it has begun to solidify as it cools down from the melting temperature. The latter simulates the molten pool behaviour of the deposited metal to reveal mechanical information on how the microstructure and 
grain formation take place as the material transforms from liquid to solid. In this work, since residual stresses and distortion comprise the intended output, the mechanics of solids approach has been adopted to analyse AM as well as the other reported post-process operations.

One of the main branches of AM is a manufacturing method called laser powder bed fusion (L-PBF), which is based on the laser melting of sequential thin layers of metal powder on a flat bed. Every time the laser melts a layer of metallic powder, the powder bed is refreshed by adding an additional thin layer of powder and raking it flat again. The AM process reported in this paper is L-PBF.

The finite element (FE) approach has been applied to simulate the process of L-PBF as well as the reported post-process operations. In general, AM can be modelled with the FE method by adopting either the thermomechanical [1] or the inherent strain approach [2]. The thermo-mechanical approach relies on either a classic FE thermal analysis or an analytical temperature field, leading to the calculation of residual stresses and distortion. In either case, the thermo-mechanical approach requires the numerical modelling approximation of "lumping" layers together to achieve a realistically efficient simulation and avoid having prohibitively large FE models [3].

HT is a common post-process procedure that can be applied to components with excessive residual stresses. The deliberate increase of temperature, hold time at a material-specific high temperature and the subsequent return to room temperature typically mitigate residual stresses and can cause the metal to achieve a favourable material tempered state. The mechanism of HT relies on the metal changing its material properties at high temperature. When the temperature of the metal is increased to typically $50 \%$ to $70 \%$ of the melting point, the yield strength of the material is substantially decreased, resulting in an immediate reduction in the residual stress field (any stress exceeding the new yield stress value). During the subsequent hold time at the high temperature, the metal goes through a process of creep, resulting in a significant relaxation of the entire residual stress field. The metal is then cooled down, back to room temperature, accompanied by an increase in the yield strength of the material, which results in a redistribution of the residual stress field and a limited increase in residual stresses at some locations [4].

In contrast to HT, both SP and LSP methods are used to induce a compressive stress profile on the surface of a component. LSP is a cold working process $[5,6]$, whereby short laser pulses are directed onto the surface, the impact of which will create a plasma as material is ablated and the laser's energy converted. In atmospheric conditions, much of the energy would be dispersed rapidly; however, if a tamping or containing layer is used, the plasma is constrained and a greater amount of energy will be directed into the underlying material. The compressive wave can potentially change the microstructure of the material and work-harden the surface. Secondary outcomes from LSP include increased fatigue life, resistance to fretting or wear and corrosion resistance [7].

Simulation of the LSP process has received significant attention in recent years, particularly for predicting the dynamic material response, final stress field after processing and prediction of fatigue life. Due to the rate of impact, the energy released and the complex nature of amplitudes, the material response to LSP is highly dynamic and therefore challenging to model.

There is less agreement on the most suitable means of calculating the residual stress from highly dynamic interactions and deformations. Bhamare et al. [12] modeled the laser pulse as a transient pressure in a dynamic step. In a second step, the traveling elastic waves in a component were dissipated using an artificial damping to obtain steady-state solution and predict the residual stress state. Keller et al. [8] also modeled the laser pulse as a transient pressure in a dynamic step, but they used an implicit static step to obtain a new stress equilibrium. 
The inherent strain approach, and closely related eigen strain $[9,10]$, methods are perhaps the most utilised; they relate the non-elastic strain produced during dynamic loading to the final residual stress by using the Hooke's Law. Dislocation simulation has also been used to represent the buildup of plastic strain in materials and the subsequent prevention of elastic recovery [10,14]; the approach employs molecular modelling to represent both the atomic constitution of the material and the creation/ migration of dislocations after laser peening.

SP is another cold working process used in industry to induce compressive stresses at a free surface. The process involves the bombardment of a target surface with hardened spherical "shots" at high velocities to create plastic deformation. This results in small scale indentations on the target surface, which leads to a compressively stressed layer around the part. The layer of compressive stress aids the delay (or prevention) of surface cracks and in turn improves the fatigue life of the peened part [15].

Experimental research regarding SP has been carried out for several decades to further understand the mechanics of the process for Inconel 718 alloy [16, 20], aluminium alloys [17, 18] and hardened steel [19]. The result of SP is dependent on numerous parameters such as shot size, velocity, shape and hardness. In addition, other factors include angle of impact, duration of shot peening and even the interaction between the shots themselves. Typically, if the fatigue performance of a peened part is adequate then subsequent parts are peened with the same process parameters. However, refining the parameters needs to be carried out by further experimentation if the part does not meet fatigue life criteria [21]. This process is often time consuming and expensive. These issues coupled with advances in High Performance Computing (HPC) technology in recent years have led the engineering community to turn to simulation to shed light on the mechanics of the process. Numerical simulations can provide relevant detail and require less effort to carry out parametric studies of the process [15].

It is evident that researchers have developed new methods and techniques to model the non-linearity of AM, HT, LSP and SP. Many of these techniques have been successfully validated and adopted in industry. Also, there have been studies that investigate process chain modelling. Afazov et al. [22] simulated a manufacturing processes chain of an aero-engine disc component including an oil quenching process followed by ageing, macro-scale machining, micro-scale machining and shot-peening. Tersing et al. [23] demostrated a simulation of an aero-engine vane including metal forming, metal deposition, macro-machining, welding, heat treatment and roller burnishing. However, no process chain modelling has been carried out on manufacturing applications of AM to the knowledge of the authors. Therefore, the novelty of this paper is to demonstrate a methodology that enables the numerical simulation of AM process chains and address some of the key challenges highlighted in the UK National Strategy for Additive Manufacturing [24].

This study presents the modelled process chain of an industrial impeller, following validation of the simulation methodology using a double cantilever beam. In the reported work, the processes of AM and subsequent HT have been numerically modelled by applying the FE method, using the commercial software package ABAQUS [4]. The inherent strain approach has been adopted for the modelling of AM [25]. Norton Creep Law has been adopted for the modelling of creep in HT [26]. The FE models of AM and HT are validated against experimentally measured distortions from an AM built double cantilever beam and impeller. The paper reports the simulated impeller process chain and double cantilever beam validation, describing the FE residual stresses and distortion induced by AM and HT, and further modified by one of two different post processes, SP and LSP. The post process models have been validated/calibrated individually for this study.

It must be noted that the modelling and simulation of individual processes, such as AM, heat treatment and surface work-hardening, have progressed remarkably in the last few years with the advancement of computing 
power and simulation software packages. This has led to the publication of many scientific articles, as referenced above, discussing numerous aspects about each individual process. In real manufacturing applications however, processes do not take place in isolation, but instead are linked together and executed in a certain sequence to obtain the final product as described in predetermined design specifications. Therefore, this paper has been scoped accordingly, describing the interaction between manufacturing and post-process operations, and demonstrating how specific details are processed and transferred from one numerical model to the next in order to achieve an overall comprehensive and informative outcome. For such an approach, relevant technical information relating to the chain aspect of the simulation is presented, making the manuscript relevant to readers who would be interested in analysing complete manufacturing process chains.

\section{Overview of Process Modelling Techniques}

The following subsections give an overview of the FE modelling methodologies applied to the process chain of an AM manufactured impeller.

\subsection{FE Modelling of Additive Manufacturing (AM)}

The FE method has been applied to simulate the build process of a double cantilever beam and impeller in ABAQUS using the inherent strain method. The inherent strain method consists of directly applying strain values in the FE model instead of using the traditional method of predicting temperature and using a thermal expansion model to compute the thermal strains. The fundamental question when using the inherent strain method is what strain value needs to be applied in the FE model. Some researchers have applied anisotropic inherent strain values and then used the Hooke's law of elasticity to calculate the stresses [27]. This modelling approach using the theory of elasticity only requires very precise values for the inherent strains in the three Cartesian directions in order to calculate the normal and shear stresses.

In this study, a constant compressive inherent strain is applied based on the ratio between the yield stress and modulus of elasticity. The idea behind this approach is that the applied strain will be sufficient to reach plasticity in the material. Once the plasticity is reached based on the von Mises criterion, the plasticity calculations are executed and the normal and shear stresses are calculated based on the applied plasticity model. An elastic perfectly plastic material model is applied to conduct the plasticity calculations in this study. Therefore, a calibration step is introduced to gain confidence in the applied yield stress and modulus of elasticity. A double cantilever beam component is used to obtain the values for the yield stress and modulus of elasticity. The geometry of the double cantilever beam (length of $112 \mathrm{~mm}$, width of $10 \mathrm{~mm}$ and height of $10 \mathrm{~mm}$ ) has been sliced with $1 \mathrm{~mm}$ layers. The sliced geometry has been then meshed with 173,101 four-node linear tetrahedral 3D solid elements with approximate dimension of $1 \mathrm{~mm}$. The inherent strain value prescribed in the model for IN718 in the three Cartesian directions is -0.0042353 , equivalent to the negative value of dividing the yield stress of the material (720MPa) by the elastic modulus (170GPa). The inherent strain values have been applied per activated layer using the UEXPAN subroutine in ABAQUS. The activation of layers has been done using the element birth technique where all elements in the layer are activated in the stiffness matrix. Once the elements have been activated, the inherent strain values are applied by the UEXPAN subroutine in the form of a strain increment per layer. The strain increment is applied to the activated elements just once.

The double cantilever beam was produced by L-PBF on the Renishaw AM250 machine. Once built, the double cantilever beam was cut from the baseplate using wire electro discharge machining. The vertical distortion at the top surface of the removed double cantilever beam was measured using the shadowgraph method. The maximum measured and predicted vertical distortions after cutting the double cantilever beam 
from the baseplate were between $0.84 \mathrm{~mm}$ and $0.87 \mathrm{~mm}$, respectively. A correlation between measured and predicted distortion is shown in Figure 1 proving the validity of the model approach and the assumptions made on the yield stress and modulus of elasticity.

The same modelling approach and assumptions have been applied to the impeller component including the same slicing of $1 \mathrm{~mm}$ layers and meshing with $1 \mathrm{~mm}$ four-node linear tetrahedral 3D solid elements. The FE mesh of the impeller consists of 364,765 elements (see Figure 2). The only difference compared to the double cantilever beam is the geometry of the impeller. The impeller was built on the Renishaw AM250 machine also. Once built, the impeller was removed from the baseplate and then optically scanned using optically scanning technology to obtain the geometrical changes after L-PBF and removing from the baseplate. The scanned surfaces have been then aligned to the original geometry used for L-PBF to calculate the distortion deviations (displacement vector in the normal direction). The same approach has been used for the FE model of the impeller where the predicted FE displacements have been used to modify the initial coordinates of the FE mesh. This has resulted in a deformed mesh which has been aligned to the original geometry to calculate the distortion deviations. The surface deviations obtained by aligning the optically scanned measurements and FE predictions to the nominal geometry are compared and shown in Figure 2.

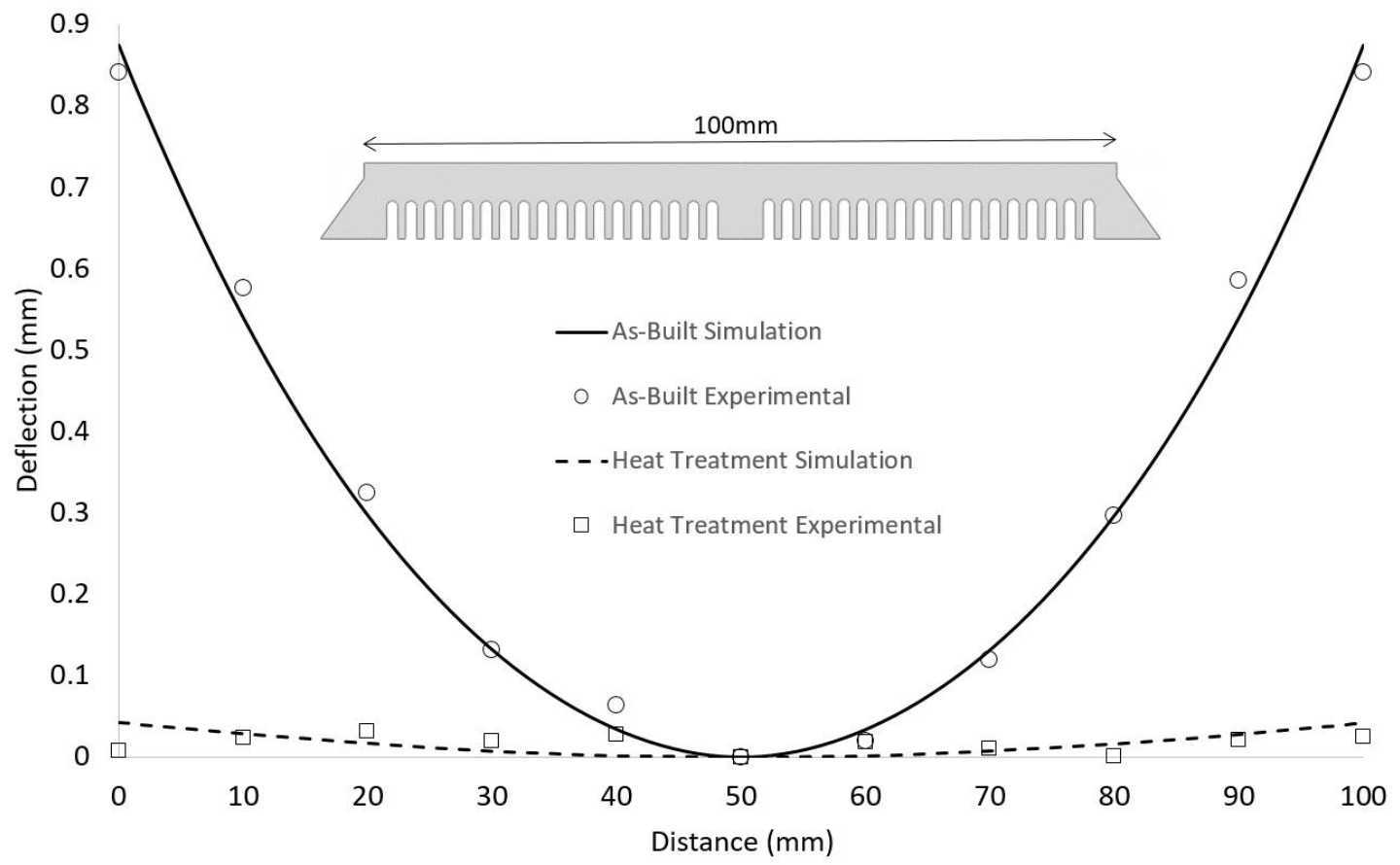

Figure 1 Comparison of predicted and measured deflection in the vertical diraction for a double cantilever beam after AM with and without heat treatment (HT) 


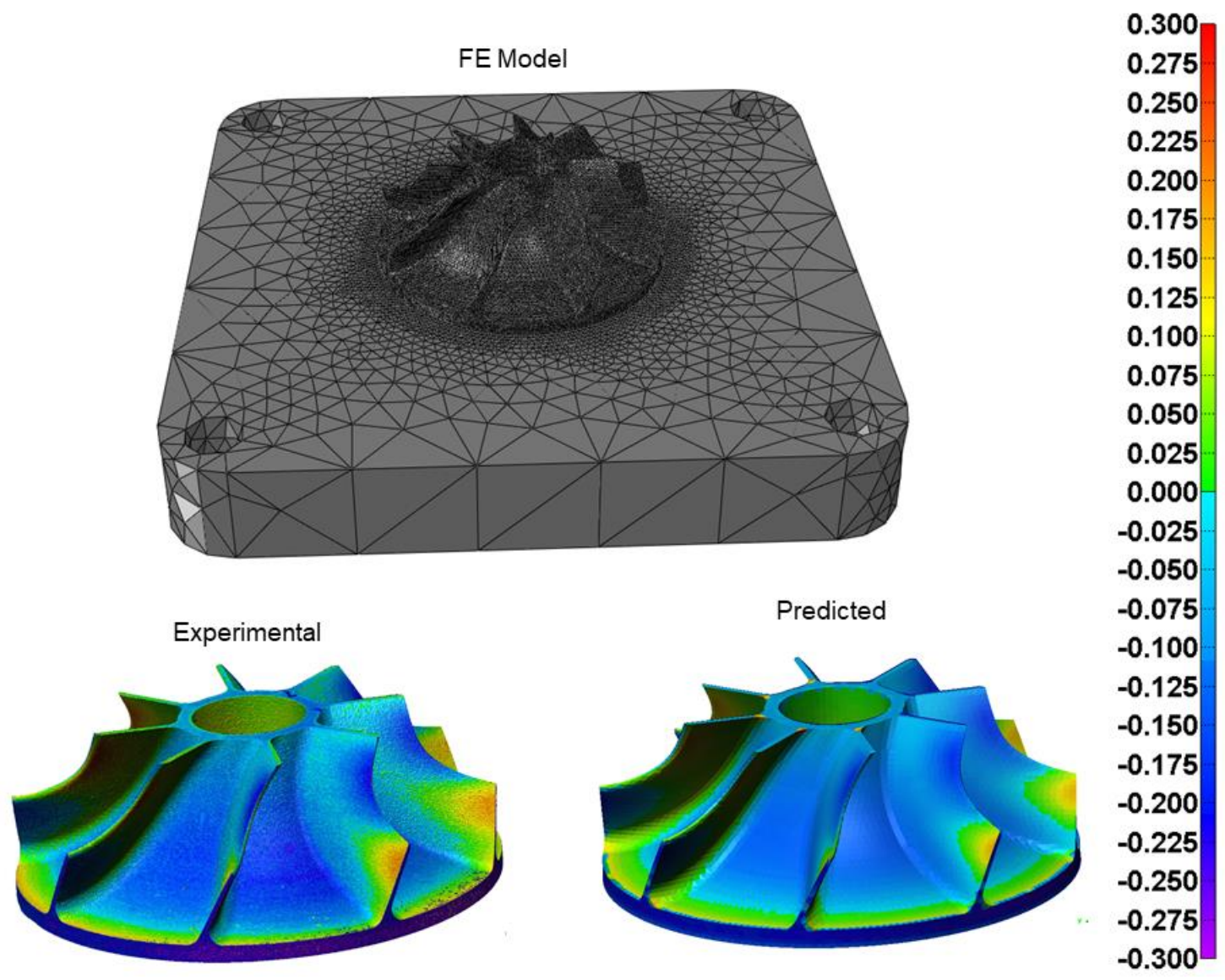

Figure 2 Comparison of opticall scanned and FE predicted surface deviation in mm after AM and baseplate removal.

\subsection{FE Modelling of Heat Treatment (HT)}

The HT process for IN718, particularly the stress relief, consisted of heating up to $980^{\circ} \mathrm{C}$, holding at that temperature for 150 minutes and then cooling down to room temperature. In this study, it is assumed that uniform heating and cooling is applied. The modelling of the heating and cooling steps are conducted by prescribing the heating and cooling thermal cycles directly into the mechanical FE model by ramping the heat up for the heating step and ramping it down for the cooling step. The prescribed temperatures are then used in a mechanical FE model to calculate the evolution of the thermal stresses. The Norton creep law is used to model the stress relief in the holding step (see Eq. 1) [26].

$$
\dot{\varepsilon}=A \sigma^{n}(\text { Eq. } 1)
$$

where $\dot{\varepsilon}$ is the strain rate, $\sigma$ is the applied stress, A and $\mathrm{n}$ are creep constants. The applied stress is represented by the residual stresses from the L-PBF. 
One of the challenges in modelling the HT process is to obtain representative material properties for L-PBF, including temperature dependent mechanical properties for the heating and cooling steps, as well as the creep properties during the holding step. The temperature dependent material properties are provided in Table 1 . The Norton creep constants used in this study are $\mathrm{A}=2.05 \times 10^{-15}$ and $\mathrm{n}=5.53$ (units in MPa and seconds) adopted from [28]. The constants corresponding to $980^{\circ} \mathrm{C}$ have been prescribed in the mechanical FE model. To validate the assumed material properties, another double cantilever beam was built on the Renishaw AM250. After the build, the double cantilever beam was placed into a furnace for HT using heating to $980^{\circ} \mathrm{C}$, holding for 150 minutes and cooling down to room temperature. After cooling, the double cantilever beam was removed from the baseplate using wire electron discharge machining and the vertical deflection has been measured. The same process has been simulated by the FE model where the same mesh from the L-PBF FE model has been used. The residual stresses and nodal displacements calculated in the end of the L-PBF have been used as initial conditions in the HT model. The predicted and the experimentally obtained vertical displasments are shown in Figure 1. The validation in this study is based on prediction of distortion assuming that the stresses are valid as well.

Figure 3 shows the stress evolution on the top surface of the double cantilever beam at different stages of the simulation. It can be seen that the maximum principal stresses are approximately $800 \mathrm{MPa}$ at the end of the L$\mathrm{PBF}$ simulation. The stresses decrease to approximately $135 \mathrm{MPa}$ after heating to $980^{\circ} \mathrm{C}$. This decrease is due to the decrease of the yield stress by increasing the temperature as shown in Table 1 . The stresses further decreases to approximately $15 \mathrm{MPa}$ during the holding step due to creep. After cooling, the maximum principal stresses approximately doubled to 30MPa. After removal from the baseplate, the principal stresses at the middle of the top surface have decreased. This decrease corresponds to the energy release that has generated the deflection in the vertical direction after removal from the baseplate (see Figure 1).

The same modelling methodology has been applied to the impeller geometry, the results of which are shown in Section 3.

Table 1: Temperature dependent material properties for IN718

\begin{tabular}{|l|l|l|l|l|}
\hline Temperature, ${ }^{\circ} \mathrm{C}$ & $\begin{array}{l}\text { Modulus } \\
\text { Elasticity, GPa }\end{array}$ & Poisson's ratio & Yield Stress, MPa & $\begin{array}{l}\text { Thermal expansion, } \\
\mu \mathrm{m} / \mathrm{m}^{\circ} \mathrm{C}\end{array}$ \\
\hline 20 & 170 & 0.284 & 720 & 13.7 \\
\hline 100 & 170 & 0.284 & 685 & 13.8 \\
\hline 200 & 170 & 0.284 & 643 & 13.9 \\
\hline 300 & 167 & 0.284 & 618 & 14.4 \\
\hline 400 & 163 & 0.284 & 595 & 15.2 \\
\hline 500 & 154 & 0.284 & 579 & 16.2 \\
\hline 600 & 149 & 0.284 & 562 & 17.4 \\
\hline 700 & 142 & 0.284 & 546 & 18.7 \\
\hline 800 & 138 & 0.284 & 530 & 19.9 \\
\hline 900 & 111 & 0.284 & 268 & 21.0 \\
\hline 1000 & 79 & 0.284 & 81 & 21.6 \\
\hline
\end{tabular}




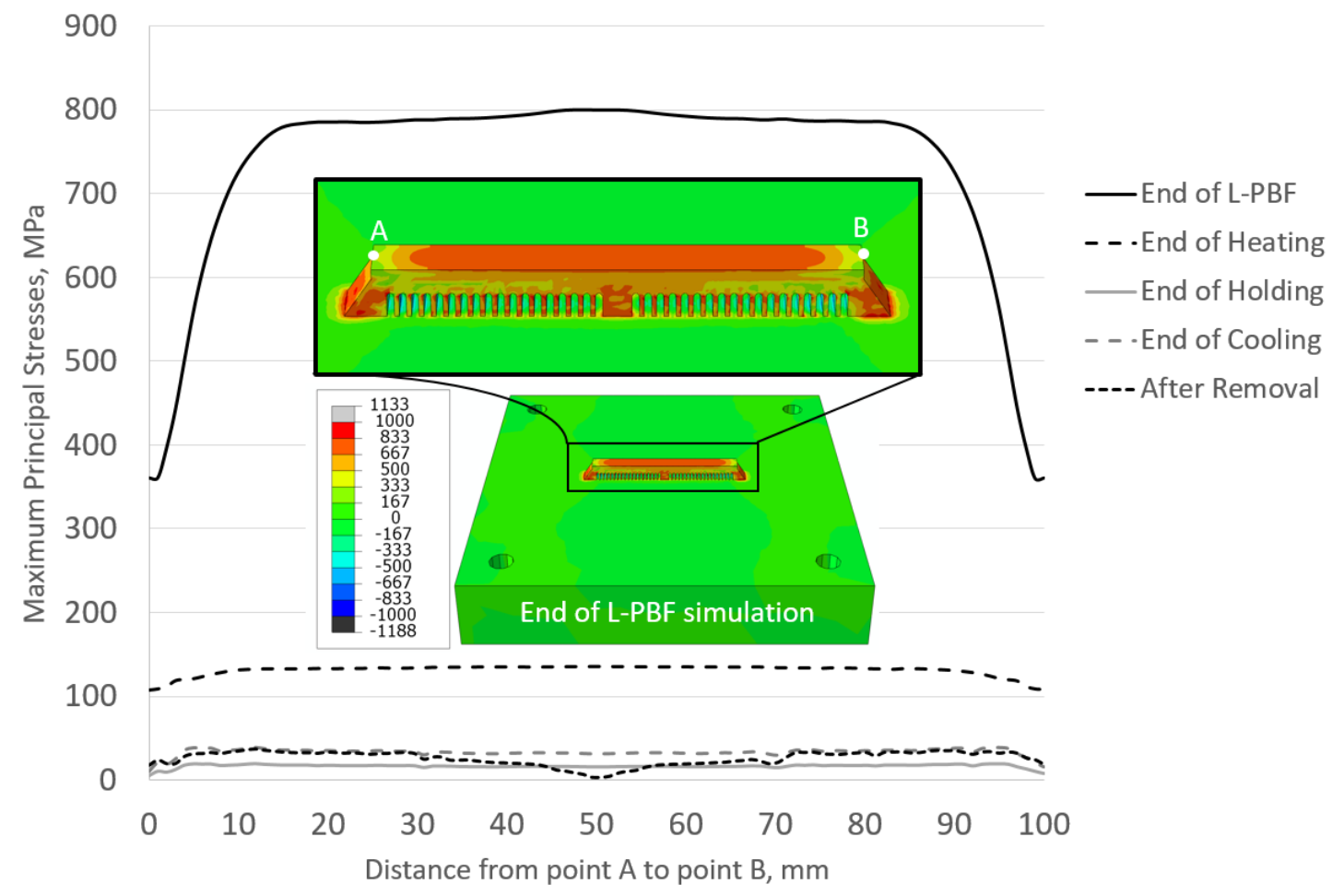

Figure 3: Stress evolution in HT of a double cantilever beam

\subsection{FE Modelling of Laser Shock Peening (LSP)}

Simulation of the LSP process has received significant attention in recent years $[8,9,10,11,12]$, with attention on predicting the dynamic material response, final stress field after processing and prediction of fatigue lifetime. Due to the rate of impact, the energy released and the complex nature of amplitudes, the material response to LSP is highly dynamic and therefore challenging to model. The most referenced constitutive model is the Johnson-Cook rate dependent yield criterion (Eq. 2) and is shown below:

$$
\sigma_{y}=\left[A+B \varepsilon^{n}\right]\left[1+C \cdot \ln \left(\frac{\dot{\varepsilon}}{\dot{\varepsilon}_{0}}\right)\right]\left[1-\left(\frac{T-T_{a}}{T_{m}-T_{a}}\right)^{m}\right]
$$

Where $\varepsilon$ is plastic strain, $\dot{\varepsilon}$ is the strain rate, $\dot{\varepsilon}_{0}$ is the reference strain rate, $\mathrm{T}$ is the material temperature, $\mathrm{T}_{\mathrm{a}}$ is atmospheric temperature, $\mathrm{T}_{\mathrm{m}}$ is the melting temperature, and $\mathrm{A}, \mathrm{B}, \mathrm{C}, \mathrm{n}, \mathrm{m}$ are material constants that need to be derived experimentally. The equation above represents the dependency of yield on the magnitude of strains, the rate of deformation and the effects of thermal softening of the material; the latter term will be simplified to $\left(1-\left(\mathrm{T}^{*}\right)^{\wedge} \mathrm{m}\right)$ as the current process is a cold working one.

The aim of the LSP simulations is to calculate the residual stress profile resulting from a surface treatment. Two simulation stages are used to quantify the effects of LSP: stage one to represent the dynamic loading and material response, stage two to calculate the final residual stress. The first stage utilises a dynamic explicit 
simulation of multiple shock waves impacting the surface of the material. An elastic perfectly plastic material model was applied. These multiple shocks will induce a plastic strain in the material. The plastic strains are then utilised in a static linear expansion simulation which will calculate the residual stress in the material corresponding to the plastic strains encountered.

The dynamic loading of the surface is performed in Abaqus Explicit. Prior to simulation the loading calculations must be identified, evaluated and applied to the case in question. Abdullahi et al. [7] have conducted an in depth review and comparison of LSP and LP, including the calculation of laser energy, its conversion to plasma and the resultant pressure wave created. Two equations in particular are vital for simulation of LSP: calculating the laser intensity and calculating the maximum pressure occurring as a result.

Laser intensity is a function of the machine parameters used to deliver the shock and can be calculated once per simulation. The equation below (Eq. 3) is taken from Guo et al. [29] for calculating the intensity of the beam. The average power output of the laser was measured using an optical power sensor; however for this paper, the average power was calculated based on machine specifications.

$$
I=\frac{P_{\text {avg }}}{f\left(p_{t}\right) a}
$$

Where $I$ is the laser intensity $\left(\mathrm{GW} / \mathrm{cm}^{2}\right), P_{\text {avg }}$ is the average power of the laser, $f$ is the operating frequency $(\mathrm{Hz}), p_{t}$ is the pulse time (ns) and $a$ is the total area of contact for the impact $\left(\mathrm{cm}^{2}\right)$. The laser intensity can be used to calculate the maximum pressure applied to the surface of the material and is again calculated once per simulation, the equation for which can be seen below:

$$
P_{\max }=1.65 \sqrt{I}
$$

Where $\mathrm{P}_{\max }$ is the maximum pressure $(\mathrm{GPa})$ and $\mathrm{I}$ is the laser intensity $\left(\mathrm{GW} / \mathrm{cm}^{2}\right)$. These calculations are included in a user defined subroutine, VDLOAD. The subroutine will apply a Gaussian distribution, defined by Eqn. 5, based on $\mathrm{P}_{\max }$ which will occur at the centre of the distribution and with a radius defined by the laser lens used. Each step will apply a new distribution, to represent multiple shocks spaced around the surface of the component. The duration of the shock-load corresponds to the pulse length of the laser and is applied using an amplitude to ramp the pressure up to maximum and back down to the zero-point, the peak occurs at 3.6ns of a $12 \mathrm{~ns}$ interaction. The laser intensity used for the validation case with stainless steel was $7.2 \mathrm{GW} / \mathrm{cm}^{2}$ and $5 \mathrm{GW} / \mathrm{cm}^{2}$ for the IN718 case.

$$
P=F(t) \times P_{\max }\left(1-0.5 \sqrt{\frac{x^{2}+y^{2}}{r^{2}}}\right)
$$

The percentage overlap, the number of interactions and the shock pattern can be represented by controlling the radius of the contact region and the reference node used for the Gaussian distribution. These factors will significantly affect the residual stress field and are the focus of a number of recent studies [30, 31, 32]. Ancillary results from LSP will be an alteration of the surface roughness and profile, Salimianrizi et al. [30] have shown that overlap must be used with circular laser distributions to prevent raised regions between them.

For LSP modelling of Inconel 718, a maximum pressure of 4GPa was used with a shock-radius of $2 \mathrm{~mm}$ and applied with the DSLoad command. The amplitude was non-uniform peak reaching a maximum at $3.6 \mathrm{~ns}$ and returning to zero at $12 \mathrm{~ns}$. The step time was $100 \mathrm{~ns}$ to represent a movement of the part/ base and to allow 
diffusion of the major shock-waves from previous interaction. Overlap was set to $20 \%$ and a total of 9 shocks were applied to result in an even distribution in the centre of the surface.

All shocks were applied in one explicit simulation. The plastic strains were extracted for the whole model and used as an input to the residual stress calculation.

The material model is Inconel 718 whose plastic response is controlled by the following Johnson-Cook parameters: $\mathrm{A}=720 \mathrm{MPa}, \mathrm{B}=1200 \mathrm{MPa}, \mathrm{n}=0.6, \mathrm{~m}=1.27$ and $\mathrm{C}=0.04$. The elastic behavior is represented by a Young's Modulus of $170 \mathrm{GPa}$, a Poisson's ratio of 0.33 and the material density is $8200 \mathrm{~kg} / \mathrm{m}^{3}$. As discussed earlier, the speed of the laser pulses allows the assumption of a cold working process and therefore the thermal dependency of Johnson-Cook does not need to be considered.

The geometry is created using rectangular section extrusion which is then meshed with refinement in all three directions. The dimensions of the cuboid are $25 \mathrm{~mm}$ by $25 \mathrm{~mm}$ by $5 \mathrm{~mm}$; the refined zone in the centre of the cuboid features elements with equilateral dimensions of $6 \mathrm{E}-2 \mathrm{~mm}$. Mesh convergence studies (see figure 4) were performed to ensure that this modelling aspect would not influence results.

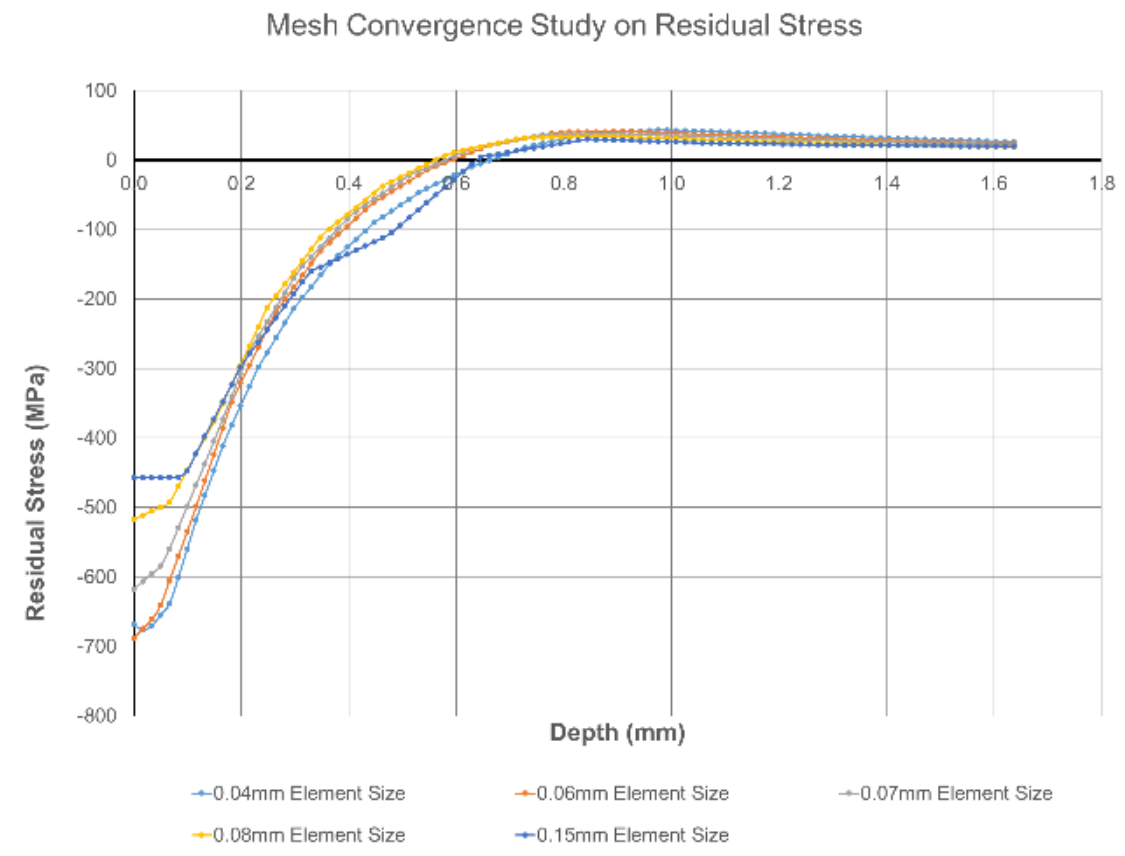

Figure 4. Mesh convergance study results.

The inherent strain method utilises the plastic strains, both primary and shear, resulting from dynamic loading. These are read into a new model with the same geometry, node and element definition, using the *Expansion keyword in Abaqus and the corresponding UEXPAN subroutine through an implicit step. No plasticity is considered in this simulation stage, it is a direct conversion of plastic strains to a corresponding 
stress that would result from an analogous change in dimension. As such the linear elastic portion of the material constitutive model is utilised in the second phase of the simulation.

The UEXPAN subroutine will apply a user-defined expansion to all selected elements in an array. It is possible to directly define both the primary and shear components of strain directly; this allows the specification of isotropic, orthotropic and anisotropic strain. For the inherent strain method, full anisotropic strains are read in from the common arrays for all elements in the model and re-applied in this stage. A single increment, over a time step of one, is utilised as it is a direct linear expansion for each element.

In this way, the strains are used to enlarge the elements against one another resulting in a stress field through the part. This corresponding stress is calculated based on the Hooke's law relationship and is the final stressed state based on the permanent deformation of the surface.

The methodology for laser shock peening using the inherent strain technique has been verified for IN718 from the experimental work of $\mathrm{Xu}$ et al. [33], as shown in Figure 5. The S11 component of residual stress is plotted in all diagrams, which coincides with the surface tangential component.

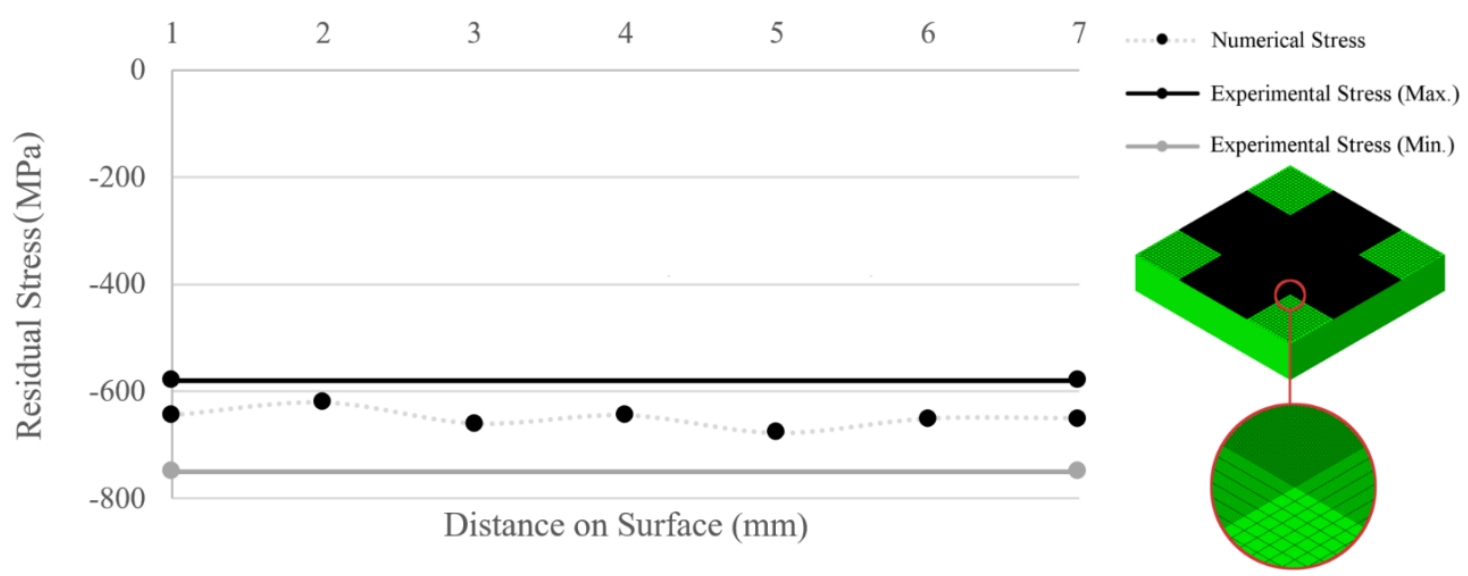

Figure 5. Comparison between experimental [33] and FE predicted surface tangential stress distribution

(S11) for IN718.

During development and validation of the LSP process, a number of material types were considered. As published results were utilised, it has been essential to replicate the extraction of data from simulations as performed in the experiments. At the time of validation, experimental results for through-depth stress were not availible for Inconel 718. For the above reasons, the simulation methodology for predicting the through depth results were validated against a 316L Stainless Steel material, while the across surface results were validated for IN718.

Figure 6 represents the validation phase for 316L stainless steel, utilising the following Johnson-Cook parameres: $\mathrm{A}=514, \mathrm{~B}=514, \mathrm{n}=0.508, \mathrm{~m}=0.533, \mathrm{C}=0.042$. The elastic behavior is represented by a Young's Modulus of $210 \mathrm{GPa}$, a Poisson's ratio of 0.33 and the material density is $7920 \mathrm{~kg} / \mathrm{m} 3$. As it can be seen, simuated results have greater correlation to the experimental results at increased depth, to $0.6 \%$ at a depth of $0.9 \mathrm{~mm}$ as opposed to an error of $12.5 \%$ at $0.2 \mathrm{~mm}$. This discrepancy under the surface is attributed to the 
complexity of the loading regime applied. Another source of variability is the selection of ablative layer used during testing. This factor can have a significant effect on the LSP process and is yet to be represented in these simualtions.

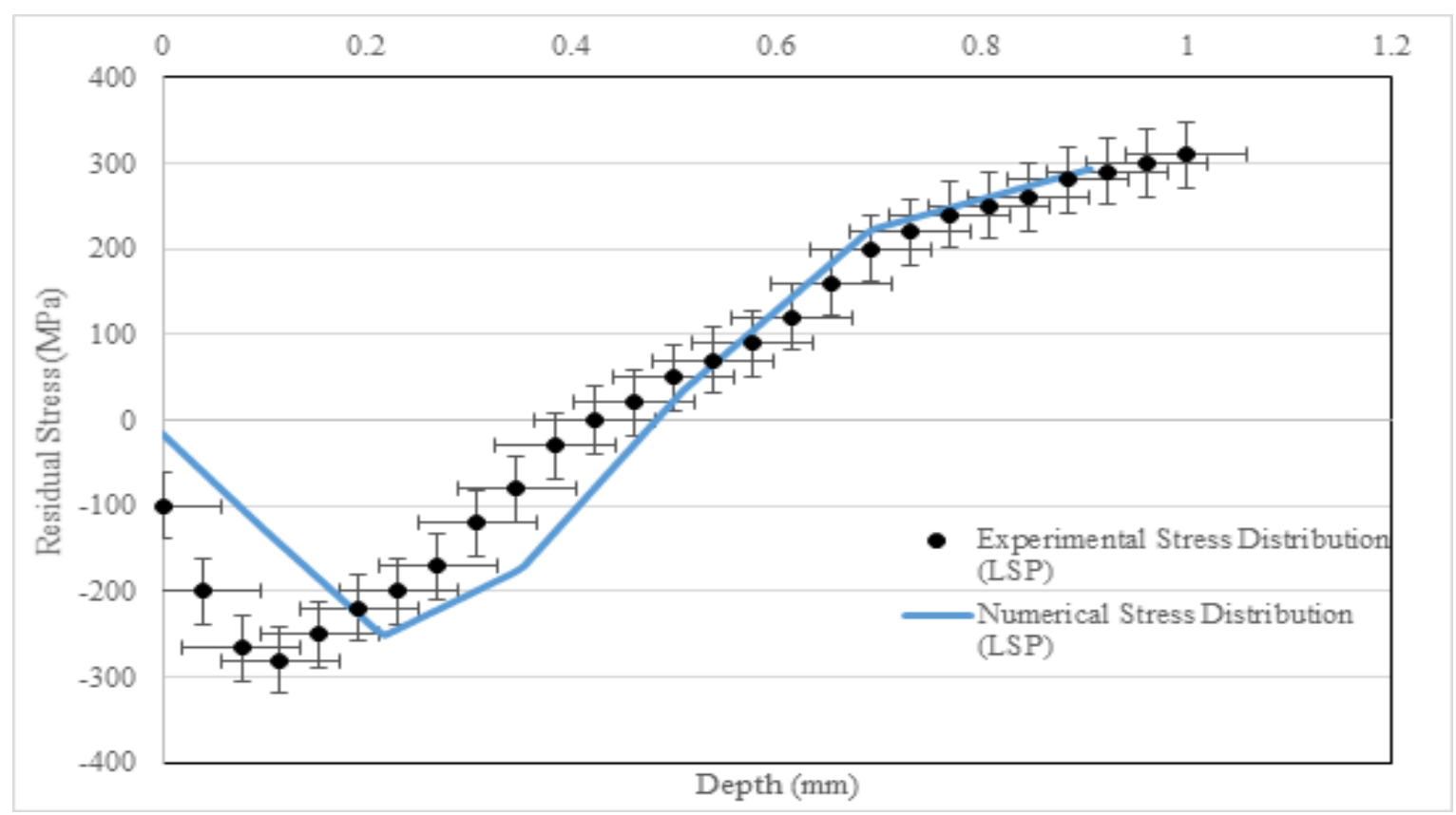

Figure 6. Validation of LSP and Inherent strain method for 316L Stainless steel from Kalentics et al. (2017) [61]

\subsection{FE Modelling of Shot Peening (SP)}

The FE modelling of the shot peening process was carried out using the ABAQUS explicit solver. The FE mesh of the SP model is shown in Figure 7, which only shows 19 of the simulated 26 shots to represent a coverage of $200 \%$ over the target area. The numerical model was calibrated against experimental data for IN718 recorded by Yijun et al. [34] with a comparison between the numerical and experimental tangential residual stress distribution (S11) shown in Figure 7. The experimental study carried out by Yijun et al. [34], utilised an ultrasonic shot peening process to peen an IN718 test specimen. SP was carried out using a Sandwell 5-axis shot peening machine with shot velocities measured by a Tecnar G3 Shotmeter. Shot velocities were recorded at $68 \mathrm{~m} / \mathrm{s}$ with maximum variation of shot speed $+/-5 \%$. The tangential residual stress within the component was measured by Yijun et al. [34] using the hole drilling method with errors in the range of +/- $50 \mathrm{MPa}$.

The model was calibrated against the experimental data for IN718 [34]. The objective of that exercise was to obtain an accurate representation of all stress components in the material. All stress components are required in order to accurately map the peening process as an input into the process chain [22]. Therefore, the magnitude and depth of compressive stresses in the FE target material needed to be representative of a physically peened 
part. A comparison between the numerically predicted and experimental tangential residual stress distributions is shown in Figure 7. The tangential residual stress was recorded up to $0.5 \mathrm{~mm}$ depth into the material surface at the centre of the impact zone.

Each shot was modelled as a rigid body with a diameter of $0.71 \mathrm{~mm}$. The shots were modelled with 3-node $3 \mathrm{D}$ rigid triangular facet elements with a velocity of $68 \mathrm{~m} / \mathrm{s}$. A rigid constraint was placed between the centre of gravity of the spherical shots (reference point) and its elements with mass and rotary inertia properties to correspond to a density of $8200 \mathrm{~kg} / \mathrm{m}^{3}$. The target surface was modelled with 8 -node linear brick elements with reduced integration and hourglass control. The properties of the target material IN718 are adapted from Afazov et al. [35] with isotropic hardening applied. Plastic response was modelling using the Johnson-Cook material model with parameters: $\mathrm{A}=870 \mathrm{MPa}, \mathrm{B}=530 \mathrm{MPa}, \mathrm{n}=0.345$ and $\mathrm{m}=0$. A friction coefficient of 0.2 similar to Mahmoudi [36], Cardozo [37] and Tu [20] was used as a contact penalty for shot impacts. Noted by Han et al. [38], friction coefficient values of 0.2 or greater have no significant influence on the residual stress profile of the target material. This was further confirmed by a study carried out by Silva [39]. Further, residual stresses are relatively insensitive to friction coefficients ranging from 0.1 to 0.5 [40, 41]. The isotropic hardening method was used to capture the material behaviour under cyclic loading.

Due to the nature of SP, the surface layers of the mesh need to be very fine in order to capture the plastic deformation and residual stress in the target surface. Noted by Bhuvaraghan [21], SP is a surface phenomenon; if the meshing of the inner material can be avoided, it will reduce the FE model size. The current study used infinite elements beyond the finite elements that absorb shock wave propagation and allow for the avoidance of meshing the inner material. The current model has 40 elements across the shot diameter. This was based on a study by Han et al. [38], where the minimum cell width should be equal to the shot diameter (D) divided by 10 . The depth of the target material is $0.625 \mathrm{~mm}$. As noted by Bhuvaraghan [21], a minimum depth of $0.375 \mathrm{~mm}$ is required for the FE model to capture the residual stress distribution through the material when the material is supported from its base. In the current study, the base of the target material had an encastre condition. Shots were positioned $0.3556 \mathrm{~mm}$ (shot radius) apart to avoid simultaneous impacts; the same value was used by Cardozo et al. [37]. All shots hit the target material at a $90^{\circ}$ impact angle with no interaction between the shots that are accounted for.

The FE model proved capable of accurately capturing the experimental stress profile to the correct order of magnitude. However, the model does underestimate the magnitude of compressive stress just below the part surface and again at a depth of $0.51 \mathrm{~mm}$. The difference between the numerical and experimental results, in particular at a depth of $0.51 \mathrm{~mm}$ was attributed to the variation in recorded shot velocity from experimental data and errors associated with the hole drilling method for recording stress distribution. Shot velocity remained constant in the numerical study and therefore did not take into account increased kinetic energy due to variations in recorded velocity (up to $+/-5 \%$ ) noted earlier. As shown by Yijun et al. [34], increased shot velocity results in a higher compressive stress value, present at a greater depth in the material, which was not captured in the current study. The difference between experimental and numerical results could have been further compounded by the error range associated with the hole drilling method (up to +/-50 MPa) noted earlier. This combined with the reduced sensitivity of the hole drilling technique at higher depths (as noted by [42]) can also attribute to the differences between results. For the purpose of this study, the stress profile was deemed sufficient in order to gain insight into the effect the preening process has on an industrial part such as the impeller during the process chain. 


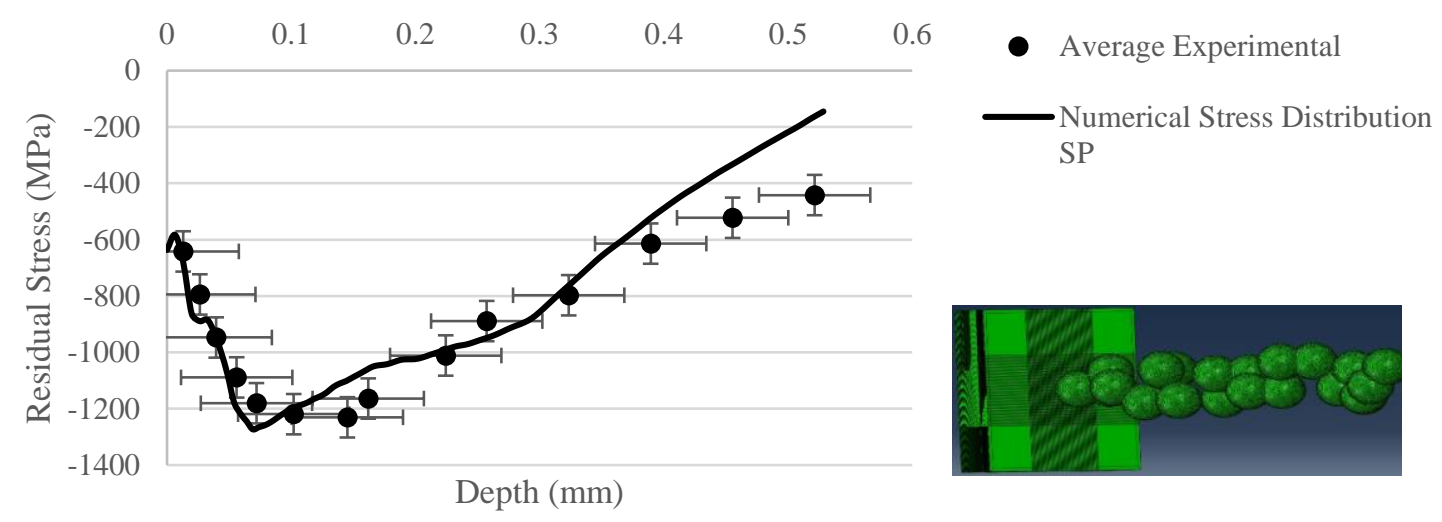

Figure 7 Comparison between experimental [34] and FE predicted tangential residual stress distribution next to an image of the FE simulation

\subsection{Overview of Mapping Techniques}

In the modelling of manufacturing process chains, data transfer between FE models is essential. Data transfer can be required between FE models with dissimilar meshes where mapping of FE data is needed. The use of mapping can introduce errors that can accumulate during the manufacturing process chain [43]. Therefore, both AM and HT have been modelled using the same mesh to minimise errors.

The SP and LSP models were validated against experimental stress profiles by comparing residual stresses in the tangential direction. Afazov et al. [35] developed a mathematical methodology for mapping peening stress profiles into components. The same methodology was used in this study to map residual stresses from SP and LSP onto the impeller after the AM and HT processes. The mapping methodology requires the profiles of all stress tensors (three normal and three shear stresses). Typically, it is difficult to measure all stress profiles at the surface and sub-surface. Therefore, after the validation of the FE models for SP and LSP, the FE predicted stress profiles have been mapped onto the impeller meshed with five uniform layers from the surface subject to peening (see Figure 8). Six-node wedge elements have been used for the uniform layers, presented in grey in Figure 8, and four-node tetrahedral elements for the rest of the mesh. 
The use of layers better captures the mapped stress profiles, which is required for complex peened surfaces. However, FE data from the HT process (stress tensors and displacements) had to be mapped onto the inflation mesh prior to mapping the LP and LSP stress profiles. The mapping of FE data was conducted using the FE data exchange system presented elsewhere [43]. After the completion of mapping, a stress rebalancing step is added to obtain the new stress equilibrium and the residual stresses following the two peening processes. The process of mapping stress profiles to components can be summarised in the following steps: (i) extract stress profiles from SP and LSP FE models; (ii) create a mesh with uniform layers under the peened surface of the impeller; (iii) apply mapping methodology [35]; (iv) obtain stress equilibrium state.

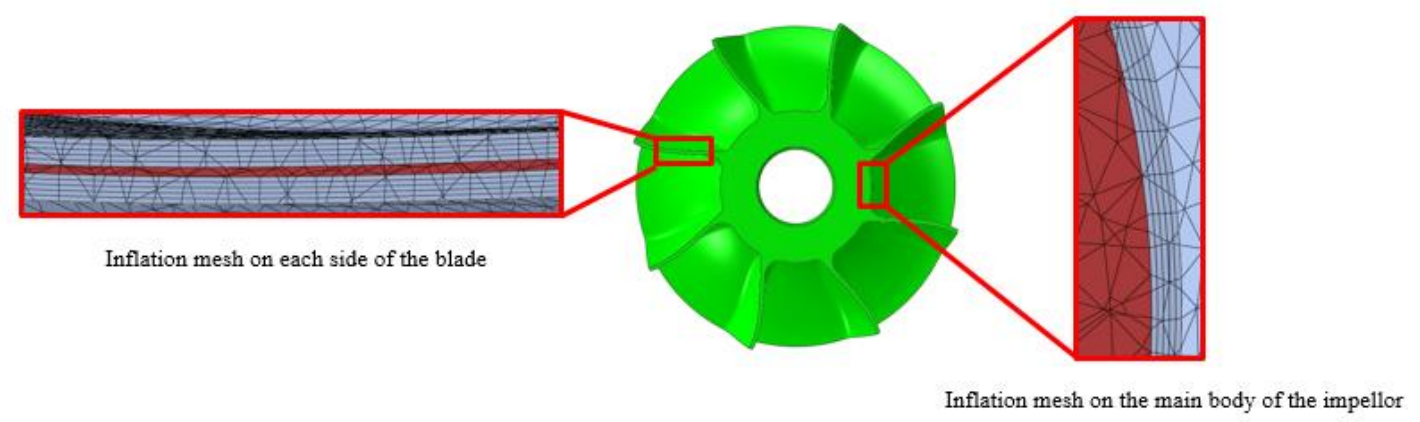

Figure 8 Inflation mesh on industrial impeller

\section{Manufacturing Process Chains}

The main objective of this research is to demonstrate a methodology for the simulation of manufacturing process chains that can be adopted for the production of industrial parts as in general. From a practical point of view, it is important to understand the benefits that this methodology can deliver during a product and process development. Figure 9 shows the simulation results of residual stress evolution in the manufacturing process chain of impeller. The figure shows the impact that each process has had on the stress evolution of the manufactured impeller (illustrated using maximum and minimum principal stresses). The evolution of residual stresses can provide better understanding of the distortion mechanisms, as well as crack formation in IN718 or other nickel-based alloys.

By analysing the AM process, which is L-PBF in the reported study, it has been observed that tensile residual stresses are generated at most of the outer surfaces and sub-surfaces, while compressive stresses have been generated inside the part. This distribution of residual stresses is typical of other manufacturing processes such as casting and hot forging. The stress values induced by AM range from $+730 \mathrm{MPa}$ (tensile) to $-300 \mathrm{MPa}$ (compressive), which are comparable to the residual stresses for an IN718 metal block reported elsewhere [23]. The location of the peak tensile stresses can be used as a map of potential micro-crack initiation for nickel-based alloys.

In many applications, it is recommended to heat treat L-PBF components in order to improve the mechanical properties and relax the stresses in the parts. In this demonstration, it is shown how the stresses after the application of HT have reduced to the region of $160 \mathrm{MPa}$ (tensile) and $-80 \mathrm{MPa}$ (compressive), which constitutes a $75 \%$ reduction approximately. For comparison, Aba-Perea et al. [44] concluded that the stress relaxation for 
ageing treatment at $750^{\circ} \mathrm{C} / 8 \mathrm{~h}$ of water-quenched IN718 is approximately $60 \%$. Rahimi et al. [45] reported a relaxation of stresses from approximately $700 \mathrm{MPa}$ to approximately $250 \mathrm{MPa}$ for aging treatment at $720^{\circ} \mathrm{C}$ of IN718 specimens. Considering the complexity of the stress distribution in the impeller, it can be concluded that the predicted stress relaxation in the impeller is comparable with published experimental results. One of the obvious benefits from the simulation is that the stress distribution in the impeller can be predicted and analysed for potential crack initiations. Another benefit is that the full stress evolution during the heating, creep and cooling steps can be analysed. It is not uncommon to see the propagation of micro-cracks during the heating step for some nickel-based alloys [46]. The initiation of cracks is observed when the thermal stress exceeds the ultimate stress at a given temperature [47]. Therefore, understanding the evolution of residual stresses during heat treatment is advantageous during the product and process development of AM parts. The use of simulation can provide greater understanding and enable the product development with less iterations.

In many parts produced by AM, HT can be the last step of a process chain. However, in some applications where greater mechanical performance is needed (e.g. fatigue), the application of cold working processes such as LSP and SP can induce compressive stresses at the surfaces and sub-surfaces. The modelling of applying LSP and SP to the impeller is demonstrated in this study through mapping of stress profiles on all surfaces of the impeller except the central shaft, which is not accessible for peening in practice. The rebalanced stresses after mapping are shown in Figure 9. The LSP process imposed a compressive stress of $-420 \mathrm{MPa}$, indicating that LSP is a suitable cold working process to enhance the durability of the impeller. The LSP process induced higher values of compressive stress on the main body of the impeller in comparison to the blades. This is mainly because of the thin nature of the blades, where after the rebalancing of the stresses, elastic energy is released to cause a distortion in the blades as shown in Figure 10. The SP process was more effective at inducing compressive stresses, with peak values of approximately $-1190 \mathrm{MPa}$ after rebalancing. Maximum distortion occurs at the blade tips with values of $0.012 \mathrm{~mm}$ and $0.066 \mathrm{~mm}$ for LSP and SP respectively. The predicted distortion gives better understanding of the implication of the process of cold working on thin structures, and it provides better understanding of the accumulation of distortion within manufacturing process chains, which can be mitigated and modified through distortion compensation techniques [3].

For a better understanding of the implication of peening on the thin sections of the blades, Figure 11 shows a sectional view $(\mathrm{XX})$ of the impeller where the compressive and tensile principal stresses are shown after AM, HT, SP and LSP. The impeller blades experience high tensile stress values after the AM process, with maximum stress values located towards the blade root with peak values of approximately 600MPa. Higher stress values are also predicted on the body of the impeller in the region of $850 \mathrm{MPa}$. Stress values are alleviated after the process of HT. There are localised areas of tensile stress around the blade roots and main body of the impeller as noted earlier. However, after SP, compressive stresses of approximately $-1100 \mathrm{MPa}$ are induced onto the blades at the surface. Considering the magnitude of the compressive stresses and the relatively thin geometry of the blade, a region of tensile stresses with a peak magnitude of 600MPa develops internally across the blade geometry after stress mapping and rebalancing. In service, those tensile stresses can be a source of initiation of cracks. A similar case is observed for the LSP process, where an internal layer of $140 \mathrm{MPa}$ tensile stress is generated. This lower tensile stress value was expected as the thin blade geometry was not subjected to high compressive stress loading from the LSP process in comparison to SP. The results show that peening parts at thin sections is delicate, and the use of process chain simulation tools can identify the right balance between induced compressive and tensile stresses in order to achieve optimum in-service mechanical performance. 


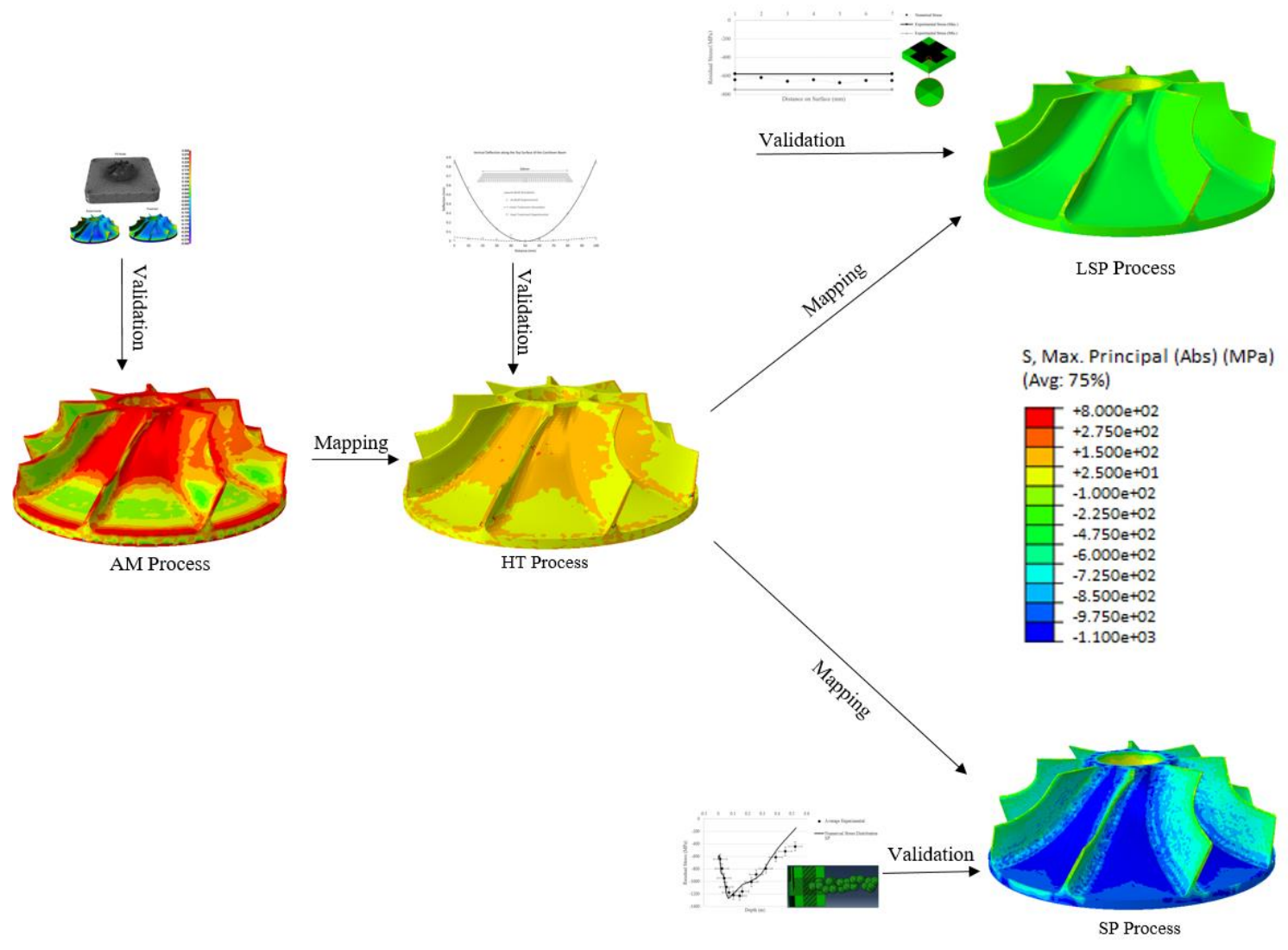

Figure 9 Graphical representation of process chain.

$U$, Magnitude

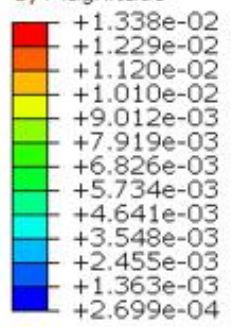

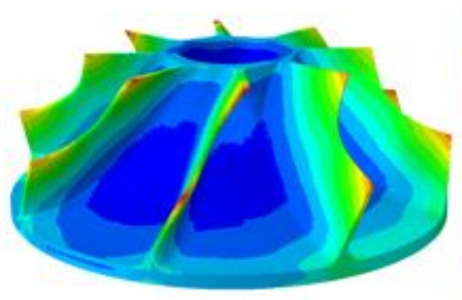

LSP Process
$U$, Magnitude
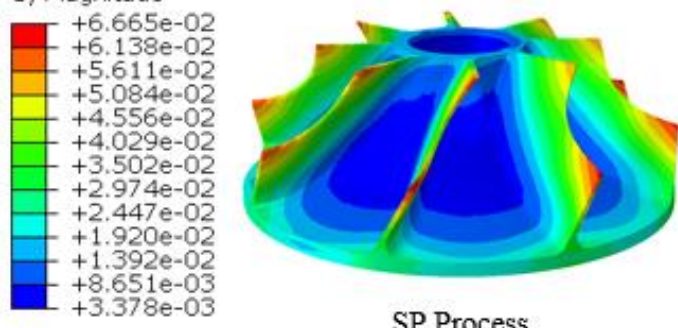

SP Process

Figure 10 Distortion of impeller post LSP and SP processes 


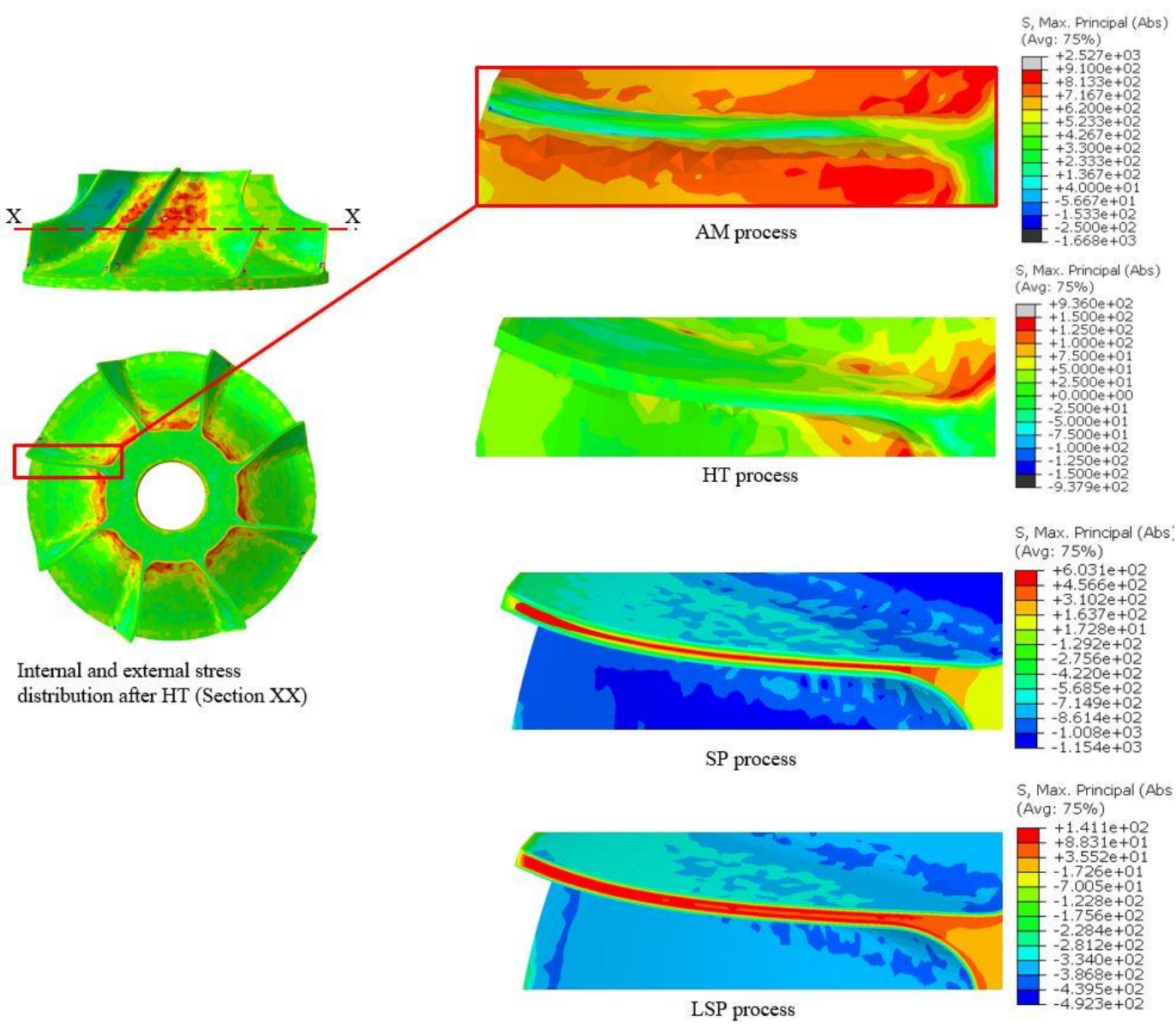

Figure 11 Internal stress distribution (MPa) of impeller blade after AM, HT, SP and LSP

\section{Conclusions}

Modelling techniques for the additive manufacturing (AM) process of laser powder bed fusion (L-PBF), heat treatment (HT), shot-peening (SP) and laser shock peening (LSP) have been demonstrated and validated in this paper. Outputs of the validated FE process models have been successfully used in the simulation of two AM process chains. The following practical conclusions have been derived based on the simulation results:

- The AM process induced residual stresses in the impeller in the range of $+730 \mathrm{MPa}$ (tensile) to -300 MPa (compressive).

- The HT process was successful at mitigating the residual stresses induced by AM, where the overall stress values reduced by approximately $75 \%$. 
- Both LSP and SP have proven capable of introducing a layer of compressive stresses around the impeller, eliminating the regions of tensile stress induced by AM and mitigated by HT. However, peening the thin blades of the impeller have induced tensile stresses inside the blades, which are not desirable for mechanical performance, such as fatigue.

The research in this study demonstrated that the simulation of manufacturing process chains is now possible, and it can be useful during the process and product development of AM parts. However, it is desirable that experimental studies are conducted in parallel with the simulations so that greater understanding is achieved during the process and product development stage of industrial AM parts.

\section{Acknowledgements}

The authors wish to acknowledge the UK High Value Manufacturing Catapult for the financial support for the development and validation of all numerical models. They also like to thank the EU H2020 ENCOMPASS project for the support with the dissemination of this research.

\section{References}

[1] Z. Luo and Y. Zhao, "A survey of finite element analysis of temperature and thermal stress fields in powder bed fusion additive manufacture," Additive Manufacturing, vol. 21, pp. 318-332, 2018.

[2] N. Keller and V. Ploshikhin, "New method for fast predictions of residual stress and distortion of AM parts," in Annual International Solid Freeform Fabrication Symposium - An Additive Manufacturing Conference, Austin, Texas, 2014.

[3] S. Afazov, W. A. Denmark, B. Lazaro Toralles, A. Holloway and A. Yaghi, "Distortion prediction and compensation in selective laser melting," Additive Manufacturing, vol. 17, pp. 15-22, 1102017.

[4] “Abaqus/Standard User's Manual, Version 6.14,” Simulia, 2014.

[5] R. Peyre, P. \& Fabbro, "Laser shock processing: a review of the physics and applications," Opt Quant Electron, vol. 27, p. 1213, 1995.

[6] J. Radziejewska, A. Sarzyński, M. Strzelec, R. Diduszko and J. Hoffman, "Evaluation of residual stress and adhesion of Ti and TiN PVD films by laser spallation technique," Optics \& Laser Technology, vol. 104, pp. 140-147, 182018.

[7] M. Abdullahi K., Gujba and Mamoun, "Laser Peening Process and Its Impact on Materials Properties in Comparison with Shot Peening and Ultrasonic Impact Peening," Materials, vol. Vol 7, no. Iss 12, pp. Pp 7925-7974, 2014.

[8] S. Keller, S. Chupakhin, P. Staron, E. Maawad, N. Kashaev and B. Klusemann, "Experimental and numerical investigation of residual stresses in laser shock peened AA2198," Journal of Materials Processing Technology, vol. 255, pp. 294-307, 152018.

[9] C. Correa, A. Gil-Santos, J. Porro, M. Díaz and J. Ocaña, "Eigenstrain simulation of residual stresses induced by laser shock processing in a Ti6A14V hip replacement," Materials \& Design, vol. 79, pp. 106-114, 1582015.

[10] V. Granados-Alejo, C. Rubio-González, C. Vázquez-Jiménez, J. Banderas and G. Gómez-Rosas, "Influence of specimen thickness on the fatigue behavior of notched steel plates subjected to laser shock peening,” Optics \& Laser Technology, vol. 101, pp. 531-544, 152018. 
[11] S. Bhamare, G. Ramakrishnan, S. R. Mannava, K. Langer, V. K. Vasudevan and D. Qian, "Simulation-based optimization of laser shock peening process for improved bending fatigue life of Ti-6Al-2Sn-4Zr-2Mo alloy," Surface and Coatings Technology, vol. 232, pp. 464-474, 15102013.

[12] Y. Liao and G. J. Cheng, "Controlled precipitation by thermal engineered laser shock peening and its effect on dislocation pinning: Multiscale dislocation dynamics simulation and experiments," Acta Materialia, vol. 61, no. 6, pp. 1957-1967, 142013.

[13] S. Coratella, M. Sticchi, M. Toparli, M. Fitzpatrick and N. Kashaev, "Application of the eigenstrain approach to predict the residual stress distribution in laser shock peened AA7050-T7451 samples," Surface and Coatings Technology, vol. 273, pp. 39-49, 1572015.

[14] S. Meng, X, Zhou, J. Huang, "Properties of a laser shock wave in AL-Cu alloy under elevated temperatures a molecular dynamics simulation study," Materials, vol. 10, no. 73, 2017.

[15] G. Majzoobi, R. Azizi and A. Alavi Nia, "A three-dimensional simulation of shot peening process using multiple shot impacts," Journal of Materials Processing Technology, pp. 1226-1234, 2005.

[16] A. Sandá, V. García Navis and O. Gonzalo, "Surface state of Inconel 718 ultrasonic shot peened: Effect of processing time, material and quantity of shot baolls and distance from radiating surface to sample," Journal of Materials and Design, pp. 2213-2220, 2011.

[17] H. Y. Miao, D. Demers, S. Larose, C. Perron and M. Lévesque, "Experimental study of shot peening and stress peen forming," Journal of Materials Processing Technology, pp. 2089-2102, 2010.

[18] A. Zaid, M. Ababneh and T. AI-Haddid, "Effect of shot peening on the fatigue strength of 2024-T3 aluminium alloy in the unwelded and welded conditions," in Current Advances in Mechanical Design and Production VII, Cairo, 2000.

[19] M. Koybayashi, T. Matsui and Y. Murakami, "Mechanics of creation of compressive residual stress by shot peening," International Journal of Fatigue, pp. 351-357, 1998.

[20] F. Tu, D. Delbergue, H. Miao, T. Klotz, M. Brochu, P. Bocher and M. Levesque, "A sequential DEM-FEM coupling method for shot peening simulation," Surface \& Coatings Technology, pp. 200$212,2017$.

[21] B. Bhuvaraghan, S. Srinivasan, B. Maffeo, R. McClain, Y. Potdar and O. Prakash, "Shot peening simulation using discrete and finite element methods," Advances in Engineering Software, pp. 12661276, 2010.

[22] S. Afazov, S. Nikov, A. Becker and T. Hyde, "Manufacturing chain simulation of an aero-engine disc and sensitivity analyses of micro-scale residual stresses," International Journal of Advanced Manufacturing Technology, pp. 279-290, 2011.

[23] H. Tersing, J. Lorentzon, A. Francois, A. Lundbäck, B. Babu, J. Barboza, V. Bäcker and L.-E. Lindgren, "Simulation of manufacturing chain of a titanium aerospace component with experimental validation," Finite Elements in Analysis and Design, vol. 51, pp. 10-21, 142012.

[24] “Additive Manufacturing UK. Leading Additive Manufacturing in the UK," 2016.

[25] A. Yaghi, S. Afazov, A. Holloway and W. Denmark, "COMPARISON OF FAST FINITE ELEMENT MODELLING TECHNIQUES FOR PREDICTION OF DISTORTION AND RESIDUAL STRESSES IN LASER POWDER BED FUSION," in Design and Manufacturing Simulation of Additive Manufacturing Components, NAFEMS Seminar, Coventry, UK, 2017.

[26] A. Yaghi, T. Hyde and A. Becker, "Finite element simulation of welded P91 steel pipe undergoing post-weld heat treatment," Science and Technology of Welding and Joining, vol. 16, pp. 232-238, 2011. 
[27] M. Bugatti and Q. Semeraro, "Limitation of the inherent strain method in simulating powder bed fusion processes," Additive Manufacturing, vol. 23, pp. 329-326, 2018.

[28] A. Thomas, M. El-Wahabi, J. Cabrera and J. Prado, "High temperature deformation of Inconel 718," Journal of Materials Processing Technology, vol. 177, no. 1-3, pp. 469-472, 372006.

[29] Y. Guo and R. Caslaru, "Fabrication and characterization of micro dent arrays produced by laser shock peening on titanium Ti-6Al-4V surfaces," Journal of Materials Processing Technology, vol. 211, no. 4, pp. 729-736, 142011.

[30] A. Salimianrizi, E. Foroozmehr, M. Badrossamay and H. Farrokhpour, "Effect of Laser Shock Peening on surface properties and residual stress of A16061-T6," Optics and Lasers in Engineering, vol. 77, pp. 112-117, 122016.

[31] V. K. Caralapatti and S. Narayanswamy, "Effect of high repetition laser shock peening on biocompatibility and corrosion resistance of magnesium," Optics \& Laser Technology, vol. 88, pp. 7584, 122017.

[32] H. Karbalaian, A. Yousefi-Koma, M. Karimpour and S. Mohtasebi, "Investigation on the Effect of Overlapping Laser Pulses in Laser Shock Peening with Finite Element Method," Procedia Materials Science, vol. 11, pp. 454-458, 112015.

[33] S. Xu, S. Huang, X. Meng, J. Sheng, H. Zhang and J. Zhou, "Thermal evolution of residual stress in IN718 alloy subjected to laser peening," Optics and Lasers in Engineering, vol. 94, pp. 70-75, 17 2017.

[34] L. Yijun, B. McGory and C. McGory, "Nanocrystallisation on the surface of superalloy In718 component with a commerical shot peening process," in International conference of Shot Peening, Montreal, 2017.

[35] S. Afazov, A. Becker and T. Hyde, "Mathematical Modeling and Implementation of Residual Stress Mapping From Microscale to Macroscale Finite Element Models," Journal of Manufacturing Science and Engineering, vol. 134, no. 2, pp. 021001-11, 2012.

[36] A. Mahmoudi, A. Ghasemi, G. Farrahi and K. Sherafatnia, "A comprehensive experimental and numerical study on redistribution of residual stresses by shot peening," Material and Design, pp. 478487, 2016.

[37] E. Cardozo da Silva, S. Button and R. Pavanello, "Finite Element Impact Modelling of Shot Peen Forming," in 21 st Brazilian Congress of Mechanical Engineering, Natal, 2011.

[38] K. Han, D. Owen and D. Peric, "A combined finite/discrete element simulation of peen forming process," Engineering Computations, pp. 92-118, 2002.

[39] E. Silva, Numerical analysis of shot peen forming of mettallic sheets, Doctoral Thesis, University of Campinas: University of Campinas, 2008.

[40] S. Meguid, I. Shaga and J. Stranart, "3D FE analysis of peening of strain-rate sensitive materials using multiple impingement model," International Journal of Impact Engineering, pp. 119-134, 2002.

[41] M. Meo and R. Vignjevic, "Finite element analysis of residual stress induced by shot peening process," Advances in Engineering Software, pp. 569-575, 2003.

[42] C. Barile, C. Casavola, G. Pappalettera and C. Pappalettere, "Analysis of the effects of process parameters in residual stress measurements on Titanium plates by HDM/EPSI," Measurement, vol. 48, pp. 220-227, 2014. 
[43] S. Afazov, "Modelling and simulation of manufacturing process chains," CIRP Journal of Manufacturing Science and Technology, vol. 6, no. 1, pp. 70-77, 112013.

[44] P. Aba-Perea, T. Pirling and M. Preuss, "In-situ residual stress analysis during annealing treatments using neutron diffraction in combination with a novel furnace design," Materials \& Design, vol. 110, pp. 925-931, 2016.

[45] S. Rahimi, M. King and C. Dumont, "Stress relaxation behaviourin IN718 nickel based superalloy during ageing heat treatments," Materials Science and Engineering A, vol. 708, pp. 563-573, 2017.

[46] M. Attalah, R. Jennings, X. Wang and L. Carter, "Additive manufacturing of Ni-based superalloys. The outstanding issues,” MRS Bulletin, vol. 41, no. 10, pp. 758-764, 2016.

[47] N. Harrison, I. Todd and K. Mumtaz, "Reduction of micro-cracking in nickel superalloys processed by Selective Laser Melting. A fundamental alloy design approach," Acta Materialia, vol. 94, pp. 5968, 2015. 